\title{
ÍNDIO JÁ SOFRE POR SER ÍNDIO: LÍNGUA E IDENTIDADE EM REDAÇÕES DE INDÍGENAS
}

\section{INDIAN ALREADY SUFFERS FROM BEING INDIAN: LANGUAGE AND IDENTITY IN INDIGENOUS COMPOSINGS}

\section{Angela Derlise Stübe* \\ UFFS}

\section{Gabriele de Aguiar** \\ UFFS}

Resumo: Este artigo analisa sentidos mobilizados sobre o ser-indígena no ensino superior em redações de sujeitos indígenas participantes do Programa de Acesso e Permanência dos Povos Indígenas (PIN) da Universidade Federal da Fronteira Sul (UFFS). Para atingir tal objetivo, foram selecionadas algumas sequências discursivas de redações elaboradas no PIN-UFFS (2016). Situamo-nos na Análise de Discurso (AD) de orientação francesa, para a qual a língua é afetada pelo político, pelo histórico, pelo social e pelo ideológico. Ao observar as redações de alunos indígenas, inquieta-nos como os sentidos sobre língua e identidade são afetados ao necessitarem adequar-se ao lugar do outro, do não-indígena. Entendemos que isso pode produzir o apagamento dessas línguas indígenas, constituintes de grupos minoritários, sem discussão da inserção institucional e das consequências para a formação dos alunos e dos professores. Os resultados apontam para uma ruptura em relação à língua materna do indígena. Ao habitar o lugar considerado do não-indígena, o indígena sofre um silenciamento de sua língua e identidade a fim de ser aceito.

Palavras-chave: Indígenas. Língua. Sujeito. Identidade.

Abstract: This article analyzes senses mobilized about the indigenous being in higher education in essays written by indigenous people that participated in the Program of Access and Permanence of Indigenous Peoples (PIN), from Federal University of Fronteira Sul (UFFS). To achieve this objective, some discursive sequences from the essays elaborated in the PIN-UFFS (2016) were selected. We are in line with the Discourse Analysis (AD) from French orientation, for which language is affected by the political, the historical, the social, and the ideological. Observing the indigenous students' essays, we are disquieted how senses about language and identity are affected by the need to adapt to the place of the other, of the non-indigenous. We comprehend that this can produce the erasure of these indigenous languages, which are constituted of minority groups, without discussion of the institutional insertion and the consequences for the students and professors'

\footnotetext{
* Doutora em Linguística Aplicada. E-mail: angelastube@uffs.edu.br

** Graduada em Letras - Português e Espanhol. Mestranda em Estudos Linguísticos/ PPGEL - UFFS. E-mail: gabi11. aguiar@hotmail.com
} 
qualification. The results point to a rupture in relation to the mother tongue of the indigenous. When indigenous inhabits the place considered of the non-indigenous, the indigenous subject undergoes a silencing of his language and identity to be accepted.

Keywords: Indigenous. Language. Subject. Identity

\section{Introdução}

Ao longo do tempo, os povos indígenas foram tendo sua cultura e sua língua fortemente influenciadas pela imposição da língua-cultura do colonizador europeu, que chegou às terras brasileiras com o intuito de colonizá-las, atendendo aos interesses econômicos, políticos, sociais e religiosos do governo Português. Na medida em que esse modelo social foi se estabelecendo e se impondo sobre os povos indígenas que habitavam as terras brasileiras, houve alteração no modo de vida e no espaço social ocupado por eles na sociedade, resultando em um espaço entre-línguas-culturas, entre a língua materna e a língua estrangeira. Por conseguinte, partimos do pressuposto de que esse contexto possibilita a ruptura dos sujeitos indígenas em relação à sua língua materna.

Para atender à demanda dos indígenas e levando em consideração o papel social das universidades públicas, foi elaborado, na Universidade Federal da Fronteira Sul (UFFS), o Programa de Acesso e Permanência dos Povos Indígenas (PIN), que visa a um processo seletivo diversificado, compreendendo as particularidades desses indivíduos e promovendo o respeito à diversidade social e étnica desses povos. Nesse sentido, ressaltamos que houve intensas reivindicações dos próprios indígenas em relação à entrada no ensino superior que os levou à conquista desse espaço. Nesse processo, um dos instrumentos de avaliação é a produção de uma redação, de tipo dissertativo-argumentativo, sobre temática específica. Dessa forma, é sobre essas produções que debruçaremos nosso estudo.

Diante do exposto, este trabalho terá como foco analisar que sentidos são mobilizados sobre o ser-indígena no ensino superior nos textos desses sujeitos. Para que isso seja possível, esses sentidos serão interpretados em redações produzidas, no ano de 2016, por indígenas candidatos ao ingresso de 2017-1, em cursos de graduação da UFFS, por meio do PIN. Foram selecionadas essas redações porque as compreendemos como possibilidades de escritas de si, pois ao dizer, o sujeito se diz, constrói identificações para si e para o outro, o que pode indiciar aspectos pertinentes à relação entre-línguas-culturas desses sujeitos. Em outras palavras, “a escrita/falar de si é, fundamentalmente, evocar outros: outro de si, outro do mesmo, outro, Outro, para constituir uma narrativa de si” (GUERRA; ALMEIDA, 2016, p. 147-148).

Os textos escolhidos para compor o corpus desta pesquisa são, exclusivamente, as redações realizadas no processo seletivo do ano de 2016. 
Decidimos focar apenas na última edição do processo seletivo para que pudéssemos aprofundar nossas análises e alcançarmos nossos objetivos. Em relação à quantidade, temos 298 (duzentas e noventa e oito) redações realizadas nesse processo seletivo, porém, ao ler e analisar todo esse material, selecionamos aquilo que nos possibilitará perceber que sentidos são mobilizados sobre o ser-indígena no ensino superior. Em um primeiro gesto interpretativo, identificamos algumas regularidades nas redações: em relação à língua, o indígena evidencia que há um conflito de estar entre-línguas-culturas, entre a língua indígena e a língua portuguesa; a contraidentificação do indígena com a imagem do índio idealizado; e, por último, notamos que há um silenciamento - ou até mesmo, uma interdição - vinda das instituições de ensino.

Do ponto de vista teórico, nós nos embasamos em um olhar discursivo com teorias que abordam o sujeito em sua constituição linguística, histórica e social. O estudo se inscreve, portanto, na perspectiva da Análise de Discurso (doravante $\mathrm{AD}$ ) de orientação francesa, para a qual a língua é afetada pelo político, pelo sócio histórico e pelo ideológico. Nessa perspectiva, compreendemos que a língua não é transparente, mas atravessada e sustentada por discursos históricos, sociais e ideológicos.

Para abarcar os pressupostos teóricos da elaboração deste estudo, abordaremos inicialmente as condições de produção do trabalho, discutindo, primeiramente, acerca da situação do sujeito indígena no ensino superior no Brasil, por meio do trabalho desenvolvido por Faustino (2006). Na sequência, contextualizaremos o PIN-UFFS, principalmente pelo fato de ser por meio do programa que o sujeito-indígena consegue habitar o lugar ocupado pelo outro - o não indígena. Nos alinhavos teóricos, traremos as teorias basilares deste estudo, questões de língua e identidade a partir dos conceitos trazidos por Pêcheux (2012), Orlandi (2008) e Coracini (2007). Da mesma maneira, ao considerarmos as redações como possibilidades de escrita de si, traremos essa noção abordada por Foucault (2009) e Guerra (2012), que auxiliarão para traçarmos nossas análises. Por último, mobilizamos a análise do corpus a fim de estabelecermos nosso gesto interpretativo e o desenrolar da trama.

\section{Condições de produção: sujeito indígena participante do PIN-UFFS}

Desde a chegada do colonizador europeu ao Brasil, os indígenas tiveram mudanças em seu modo de viver, tendo que subjugar-se ao modelo social do novo morador das terras brasileiras - o branco. Nesse contato, pressupomos que os indígenas se constituíram linguisticamente por meio do silenciamento e da interdição de suas línguas o que os levou a reaprender falar e ser em outra língua: a língua portuguesa. Esse silenciamento da língua-cultura do indígena perdura até os dias atuais, em que, nas escolas em geral, o indígena necessita assumir a língua portuguesa mesmo quando 
essa não é a sua língua materna. Para exemplificar esse silenciamento da língua-cultura do sujeito indígena, destacamos a região oeste catarinense, região de abrangência da nossa pesquisa, o lugar onde se concentra grande parte dos candidatos do PIN-UFFS, no Campus Chapecó. Nesse local, há a EEB Sapety Ko, na área Reservada aos Kainkang, na Aldeia Condá, onde os alunos indígenas têm acesso ao ensino fundamental. Ao ingressar no Ensino Médio, um grande número desses alunos passa a frequentar a EEB São Francisco, devido à falta dessa modalidade de ensino na Aldeia. Com isso, ao se inserir no espaço do não-indígena, esse sujeito indígena assume a língua portuguesa para conviver com o outro.

Nesse sentido, esses participantes às vagas universitárias estudam, em sua maioria, durante o ensino fundamental em escolas nas próprias aldeias indígenas, mantendo o contato com a língua da comunidade: a língua indígena. Porém, quando chegam ao ensino médio, esses alunos saem das terras indígenas para irem ao centro urbano, a fim de estudar em escolas básicas, nas quais a língua utilizada é somente a língua portuguesa. $\mathrm{Na}$ Terra Indígena de Toldo Chimbangue, em Chapecó/SC, também há a Escola Estadual Indígena de E.F. Fen’Nó em que os alunos indígenas realizam o ensino fundamental. Nesse contexto, Limulja (2007, p. 27) apresenta que nesse lugar a língua que predomina é o português, porém “há por parte da comunidade um forte interesse e incentivo para que a língua kaingang seja ensinada na escola. [...] O ensino da língua kaingang torna-se uma importante reivindicação da população indígena no projeto de construção de sua educação escolar indígena”.

Segundo Luciano (2006, p. 136), no Brasil, “existem atualmente 2.324 escolas indígenas de Ensino Fundamental e Médio funcionando, atendendo a 164 mil estudantes indígenas”. Diante desse cenário, podemos afirmar que "a população indígena jovem está inserida na educação básica e consequentemente buscará a educação superior” (DAMBROS, et al., 2015, p. 40853). Dessa forma, principalmente para os participantes do PIN-UFFS, a Universidade Federal da Fronteira Sul se tornou uma oportunidade para que esses jovens pudessem ingressar em uma universidade pública e popular.

No entanto, necessitamos destacar que "o debate acerca da entrada de segmentos populacionais historicamente excluídos no Ensino Superior causa polêmica, pois esbarra em questões históricas e econômicas que desde o período colonial mantiveram indígenas e negros em situação de subalternidade” (FAUSTINO, et al., 2013, p. 2). Em outras palavras, a oportunidade de entrada na universidade simboliza, de certa forma, uma maneira de reconsiderar a situação do sujeito indígena na sociedade que antes nem sequer cogitava a ideia de ingressar nesse ambiente de ensino.

É importante frisar que as políticas de educação escolar indígena se modificaram e tiveram visibilidade somente após a Constituição da República Federativa do Brasil de 1988 e a Lei de Diretrizes e Bases da 
Educação Nacional (LDB) de 1996 entrarem em vigor. Como forma de ilustrar essas modificações, trazemos abaixo um recorte do artigo 210 da Constituição de 1988:

Art. 210 - Serão fixados conteúdos mínimos para o ensino fundamental, de maneira a assegurar formação básica comum e respeito aos valores culturais e artísticos, nacionais e regionais. 2. O ensino fundamental regular será ministrado em língua portuguesa, assegurada às comunidades indígenas também a utilização de suas línguas maternas e processos próprios de aprendizagem. ${ }^{1}$

Além disso, dentre os artigos contidos na LDB, recortamos o art. 78 a fim de elucidar como é discutida a educação indígena nesse documento:

Art. 78 - O Sistema de Ensino da União, com a colaboração das agências federais de fomento à cultura e de assistência aos índios, desenvolverá programas integrados de ensino e pesquisas, para oferta de Educação escolar bilíngüe e intercultural aos povos indígenas [...]. ${ }^{2}$

Foi a partir da vigência desses documentos que "a inclusão educacional passa a ser defendida como um direito de todos e um instrumento para a ampliação da cidadania” (FAUSTINO et al., 2013, p. 2). À vista disso, entendemos que, por meio das leis que projetam as línguas indígenas, houve um maior acesso do sujeito indígena ao ensino superior, oportunizando ao candidato do PIN-UFFS a possibilidade de cursar uma faculdade. Apesar disso, frisamos que há uma incapacidade das políticas governamentais de valorizar/aceitar o diferente e uma tentativa de homogeneização dos povos indígenas, tão plurais em sua língua-cultura e história.

Sobre esse contexto de mudança na educação para os indígenas, Faustino (2006, p. 62) aponta que mesmo ao terem passados séculos da colonização, marcada por genocídios de milhares de pessoas e de intolerância em relação à diversidade racial e cultural, na atualidade busca-se, de certa forma, inserir essas minorias na sociedade por meio da educação. Todo esse processo de mudança no âmbito educacional é resultado da luta de indígenas por esse espaço na sociedade. Percebemos que a UFFS, ao garantir o acesso ao indígena, procura estabelecer ações de permanência a esse público, por meio de bolsas de permanência oferecidas pelo Ministério da Educação e Cultura (MEC) e turmas de língua portuguesa específicas para indígenas. Apesar disso, há altos índices de evasão desses alunos por inúmeros motivos: dificuldades linguísticas, inserção e receptividade dos demais colegas e, até mesmo, problemas financeiros para custear sua permanência na universidade. Nesse sentido, nos semestres iniciais da graduação cerca de 50\% (cinquenta por cento) das reprovações são motivadas por nota e frequência e, por consequência, os estudantes desistem do curso. ${ }^{3}$
${ }^{1}$ Disponível em: $<$ http://www.planalto. gov.br/ccivil_03/ Constituicao/Constituicao.htm>. Acesso em: 27 jun. 2017.

2 Disponível em: $<$ http://portal.mec. gov.br/seesp/arquivos/pdf/lei9394_ ldbn1.pdf $>$. Acesso em: 27 jun. 2017.

${ }^{3}$ Essas informações foram obtidas por meio do Relatório de Atividades do Programa de Acesso e Permanência dos Povos Indígenas (PIN), da Universidade Federal da Fronteira Sul, do ano de 2017. 
Ao ingressar na UFFS, o indígena passa a habitar o espaço considerado do outro e a conviver com a metalinguagem mobilizada pelo discurso científico - língua portuguesa da academia -, de maneira que tomamos como pressuposto da pesquisa que esse contato provoca no indígena rupturas com a língua materna, uma vez que esse sujeito, além de assumir a língua portuguesa, assume a língua da norma culta, da norma padrão e do discurso científico. Por conseguinte, acreditamos que a língua constitui o sujeito e é nessa concepção que pensamos o sujeito-indígena o qual é interpelado pela sua língua e pela língua do outro.

Em todo esse percurso traçado sobre o indígena no ensino superior, ressaltamos que só foram concedidas vagas de ingresso nesse ambiente de ensino para os indígenas após incessantes reivindicações deles próprios. Podemos ilustrar essa exigência por meio desse recorte de uma redação de um candidato do PIN-UFFS (2016) em que ele finaliza sua escrita afirmando que "vai ter sim Indígenas em Universidades! ". ${ }^{4}$ Perante a grande demanda, a Universidade percebeu a necessidade da criação de um processo seletivo que suprisse a necessidade do público da região de abrangência dos cinco campi. Apesar da UFFS abranger seis campi (Cerro Largo/RS, Chapecó/SC, Erechim/RS, Laranjeiras do Sul/PR, Passo Fundo/RS e Realeza/PR), o PINUFFS ocorre apenas em cinco deles, visto que no campus Passo Fundo há somente o curso de Medicina, o qual não disponibiliza vagas nesse processo seletivo. Dessa forma, o sujeito indígena teve a oportunidade de ingressar no ensino superior por meio do processo seletivo exclusivo realizado pela UFFS, que teve como principal objetivo oportunizar a esse futuro aluno o ingresso à universidade.

Por meio da Constituição de 1988, como já ressaltamos, os indígenas passaram a ter direitos que antes não possuíam, principalmente em relação à educação. Tendo consciência disso, as comunidades começaram “a lutar pelo acesso à educação, por entender que é por meio dela que se pode transformar uma sociedade e fortalecer a comunidade indígena na sua cultura e tradição” (DAMBROS et al., 2015, p. 40854). A universidade, ao implementar um processo seletivo diversificado para o indígena, demonstra ter consciência de que "tratar o índio como igual já é em si apagar a diferença que ele tem e que é o cerne de suas relações” (ORLANDI, 2008, p. 68), uma vez que o candidato indígena passou por um processo escolar diferente do não-indígena. Além disso, a língua portuguesa, para muitos indígenas, não é a língua materna. Esses falantes tampouco dominam a língua utilizada em discursos acadêmicos. Desse modo, optou-se por um processo seletivo específico para contemplar a singularidade desse grupo social.

Sendo assim, na próxima seção, apresentaremos detalhadamente o processo exclusivo indígena da UFFS, o PIN, o qual considera a singularidade do sujeito indígena. Do mesmo modo, nessa seção elucidaremos a constituição da redação que é nosso objeto de estudo.
${ }^{4}$ Vale salientar que esse recorte tem a finalidade de, apenas, ilustrar a reivindicação do candidato em conseguir essa vaga na universidade. A análise, de modo aprofundado, será apresentada no tópico "Como um pontinho preto no meio de vários pontinhos brancos: gesto interpretativo das redações do PIN-UFFS (2016)". 


\section{Programa de Acesso e Permanência dos Povos Indígenas (PIN) da UFFS}

O Programa de Acesso e Permanência dos Povos Indígenas da Universidade Federal da Fronteira Sul é um processo seletivo diversificado para candidatos indígenas, compreendendo as particularidades desse público. Conforme um relatório de atividades do PIN-UFFS de 2013, elaborado pela Diretoria de Políticas de Graduação (DPGRAD), o surgimento desse processo seletivo se deu devido a reinvindicações de caciques e professores das comunidades indígenas que almejavam a oportunidade de o povo indígena conquistar um lugar no ensino superior.

Desde a implantação do PIN, em 2013, a UFFS conta com alunos indígenas de diferentes etnias, com predominância das etnias Kainkang e Guarani, matriculados na instituição. Isso se deve ao fato de estas duas etnias específicas estarem localizadas na área de abrangência da UFFS 5 . Segundo dados do Sistema de Gestão Acadêmica (SGA) da UFFS, no dia 12 de setembro de 2017, em todos os cinco campi, há 68 (sessenta e oito) alunos indígenas com matrícula ativa, ingressantes pelo PIN-UFFS, dentre eles 41 (quarenta e uma) são mulheres e 27 (vinte e sete) são homens. Já no campus Chapecó, há 36 (trinta e seis) alunos indígenas matriculados, sendo 22 (vinte e duas) mulheres e 14 (quatorze) homens. Destacamos a finalidade desse processo seletivo, aprovado pelo Conselho Universitário (CONSUNI) pela Resolução No 33/2013, com o seguinte trecho:

Capítulo I: Art. 2: O Programa de Acesso e Permanência dos Povos Indígenas (PIN) da UFFS constitui-se em instrumento de promoção dos valores democráticos, de respeito à diferença e à diversidade socioeconômica e étnico-racial, mediante a adoção de uma política de ampliação do acesso aos seus cursos de graduação e pós-graduação e de estímulo à cultura, ensino, pesquisa, extensão e permanência na Universidade. (UFFS, 2013, p. 2).

Assim sendo, por meio do processo seletivo, são ofertadas 2 (duas) vagas suplementares por curso da UFFS, com exceção daqueles cursos nos quais a universidade não tem autonomia de disponibilizar vagas. Em relação à prova em si, o Edital no 820/GR/UFFS/2016 ${ }^{6}$ oferece-nos informações pertinentes sobre o processo seletivo de 2016, do qual analisaremos as redações posteriormente. Esse edital estabelece de que forma se constituirá a prova:

\section{DO PROCESSO SELETIVO}

4.1 A prova será constituída de uma redação escrita em Língua Portuguesa, com peso de até 50 (cinquenta) pontos, e de 25 (vinte e cinco) questões objetivas, envolvendo Língua Portuguesa, Matemática, História, Geografia e Ciências Naturais, com peso de até 50 (cinquenta) pontos, totalizando o máximo de 100 (cem) pontos. (UFFS, 2016, p. 4).

5 Informações obtidas no texto "Estudantes Indígenas na Educação Superior: o contexto da UFFS" (DAMBROS et al., 2015).

\footnotetext{
${ }^{6}$ Disponível em: $<$ https://www. uffs.edu.br/atosnormativos/edital/ gr/2016-0820>. Acesso em 17 jun. 2017.
} 
Além disso, o documento dá ênfase à redação em um tópico específico, o qual destaca que a redação tem caráter classificatório e eliminatório, dado que constitui 50 (cinquenta) pontos em todo o processo seletivo, como já foi destacado. Devido a isso, a redação tem por objetivo avaliar a competência do candidato de estruturar um texto e de argumentar. Da mesma forma, o aluno que fugir ao tema proposto receberá a nota correspondente a 0 (zero). Sobre os critérios de avaliação, o desenvolvimento do tema recebe uma maior pontuação se for bem construído, no caso (30,00 pontos). Já a apresentação e a estrutura textual contam com (5,00 pontos) cada um deles, totalizando (10,00 pontos) e, por último, o domínio da língua portuguesa recebe, se atender às exigências da norma padrão, o máximo de (10,00 pontos).

É perceptível que a redação preza muito mais, em questão de pontuação, pela estruturação das ideias e o desenvolvimento do tema, na avaliação do candidato, do que os demais critérios. Ressalvamos que a redação exigida é de tipo dissertativo-argumentativo, sobre temática específica que se modifica a cada processo seletivo. Ademais, o tema geralmente, como notamos nas provas anteriores, corresponde com a realidade em que o indígena está inserido. ${ }^{7}$ Em decorrência disso, no processo seletivo de 2016 foi solicitado que os pretendentes às vagas dissertassem sobre os "Desafios e expectativas sobre o ensino superior para os indígenas”. Nesse ano, foram escritas 298 (duzentas e noventa e oito) redações por, exclusivamente, concorrentes indígenas que fizeram as provas nos respectivos campi da UFFS que oferecem vagas suplementares nos cursos de graduação.

Tendo em vista a configuração do programa da universidade, é notável o empenho em propiciar aos sujeitos indígenas a oportunidade de ingressar no ensino superior, o qual compreendemos ser um "meio basilar para a formação de cidadãos aptos a promover o desenvolvimento social, justo e igualitário [...]” (DAMBROS et al., 2015, p. 40848).

Considerando a universidade - principalmente a pública, que é o nosso locus de pesquisa - um lugar de concretização de direitos, compreendemos que é dever do Estado tornar possível o acesso à educação para todos os cidadãos (DAMBROS, et al., 2015). Com a criação do PIN, indígenas tiveram a chance, ao exercer sua cidadania, de adentrar ao ensino superior e criarem expectativas de darem melhores condições de vida às suas comunidades, como ilustram inúmeras redações. Na sequência, traremos a metodologia utilizada neste estudo.
7 No processo seletivo do ano de 2014 o tema da redação foi "Reivindicações históricas dos povos indígenas brasileiros”. Já em 2015 o tema a ser dissertado pelos candidatos foi "Como você vê a relação das comunidades indígenas com os não indígenas nos dias atuais?”.

\section{A constituição do corpus e a análise das redações do PIN-UFFS (2016)}

Antes de partimos para o embasamento teórico que constitui este trabalho, é pertinente evidenciar que o presente estudo possui um desenho flexível e de base interpretativista. Ressalvamos, ainda, que esta é uma pesquisa documental qualitativa em que utilizaremos das redações do sujeito 
indígena para compor o corpus de análise. Para tanto, contatamos a Diretoria de Políticas da Graduação (DPGRAD), no campus Chapecó, a qual prontamente nos atendeu, para termos acesso às redações do PIN-UFFS, as quais foram disponibilizadas e digitalizadas.

Ao propormos interpretar marcas de regularidade nas redações no que se trata de sentidos sobre o ser-indígena no ensino superior e, por consequência, discutir como as escritas de si apontam para traços identificatórios do indígena, inicialmente fizemos um estudo bibliográfico sobre os conceitos de língua, identidade e escrita de si, por meio da AD, e assim fizemos o levantamento do aporte teórico da pesquisa.

Concomitantemente, realizamos a análise documental do material de arquivo: redações elaboradas no processo seletivo PIN, da UFFS, do ano de 2016. Pelo gesto de interpretação, buscamos, nessas redações, marcas discursivas regulares que apontam para sentidos sobre o sujeito indígena, com enfoque na relação desse sujeito com a(s) língua(s). Para isso, selecionamos três marcas de regularidades encontradas no corpus e que discutiremos adiante. O primeiro tópico condiz com a relação que esses candidatos têm com a sua situação entre-línguas-culturas. Na sequência, buscaremos interpretar como esse sujeito indígena se relaciona com processos de identificações para ingressar na universidade. E, por último, interpretamos que o contato com a língua portuguesa na escola e na universidade seja uma possibilidade de silenciamento e interdição da língua materna desses sujeitos.

Em relação ao ano e a quantidade de redações, destacamos que nosso olhar se deteve apenas às redações realizadas no ano de 2016, com entrada prevista no ano posterior (2017), para que, por meio dessas, conseguíssemos nos aprofundar em nossa pesquisa. Após a leitura e uma análise prévia das redações, foram interpretadas algumas regularidades que se adequavam com os objetivos da pesquisa. Com isso, estabelecemos algumas sequências discursivas (SD) para interpretar de acordo com aquilo que a teoria nos ofereceu. O método empregado, portanto, foi o de pesquisa qualitativa, uma vez que construímos as análises com base no referencial teórico sem qualquer pretensão de quantificá-las.

\section{Alinhavos teóricos: língua, identidade e escrita de si}

Segundo Orlandi (2013, p. 15), "na análise de discurso, procura-se compreender a língua fazendo sentido, enquanto trabalho simbólico, parte do trabalho social geral, constitutivo do homem e da sua história.” Em outras palavras, na AD a língua é considerada para além de estudos estritamente gramaticais e compreende que a língua não é transparente, mas afetada pelo sócio histórico, pelo político e pelo ideológico.

Ressalvamos, ainda, que nossa visão de língua está interligada com a exterioridade, assim como pontua Ferreira (2003, p. 197) ao caracterizar 
que a língua “[...] é lugar material de realização dos processos discursivos, onde se manifestam os sentidos”. Por consequência disso, o analista de discurso compreende que as línguas são heterogêneas, incompletas, sujeitas ao equívoco e passível a falhas, uma vez que, mesmo inconscientemente, no ato de se dizer algo falha, escapa ao enunciador. Para Pêcheux (2012, p. 53), o equívoco é considerado como fato linguístico estrutural, ou seja, "todo enunciado é intrinsecamente suscetível de tornar-se outro, diferente de si mesmo, se deslocar discursivamente de seu sentido para derivar para um outro”.

Do mesmo modo, a língua está sujeita ao silenciamento, ou até mesmo à interdição, em que se impede o sujeito de percorrer determinadas formações discursivas e que, ao dizer algo, se apagam necessariamente outros sentidos possíveis em uma situação discursiva (ORLANDI, 2007). Com isso, salientamos o fato de o indígena ter sofrido silenciamento de sua língua-cultura com a chegada do colonizador europeu, uma vez que o branco impôs a sua língua aos indígenas de modo a dominá-los. E, assim sendo, os conhecimentos correspondentes ao indígena construíram-se por meio desse apagamento, pela interdição.

Na medida em que o colonizador foi se estabelecendo e se impondo sobre os povos indígenas que viviam no Brasil, houve alteração no modo de vida e no espaço social ocupado por eles na sociedade, tornando-se um lugar indefinido, dentro de um espaço entre-línguas-culturas, entre a língua materna e a estrangeira (a do outro), desencadeando, dessa forma, certa ruptura dos sujeitos indígenas com sua língua-cultura. Consideramos, inclusive, que essa ruptura se mantenha nos dias atuais com os mecanismos mais diversos, podendo ser pelo estranhamento, pela autocensura, pela denegação, pela ultracorreção, pela irrupção de ordem corporal ou, ainda, por meio de pontos de identificação ou de (des)identificação com a língua (PAYER, 2013). Por meio desse apagamento violento, "há zonas de sentido, e, logo, posições do sujeito que ele não pode ocupar, que lhe são interditadas” (ORLANDI, 2008, p. 60).

Nesse sentido, trazemos uma questão a ser discutida sobre o conceito de língua materna: será que podemos afirmar que seria denominada língua materna porque provêm da mãe? Coracini (2007) desenvolve uma discussão sobre isso ao estabelecer uma dicotomia entre língua materna e língua madrasta, em que a primeira é "lugar de repouso, de segurança, de realização do desejo fundamental de completude” (CORACINI, 2007, p. 137). Já a língua madrasta é considerada “com todas as conotações que a palavra carrega: interditos, censura, punição, desconforto, angústia, castração, mal-estar...” (CORACINI, 2007, p. 137). Dessa forma, podemos pensar a língua portuguesa como sendo uma língua madrasta ao indígena, visto que para ingressar e ocupar um lugar na universidade é necessário deixar sua língua materna - lugar de repouso - para assumir a língua do outro e ocupar um lugar na sociedade. 
Contudo, não podemos tomar como verdade absoluta que a língua portuguesa, sendo a língua estrangeira de muitos indígenas, seja a tal língua madrasta para todos igualmente, em razão de que a língua não é homogênea, tampouco a identidade é fixa. Inclusive, para algumas comunidades indígenas, como a etnia Kaingang da Terra Indígena de Toldo Chimbangue, localizada no oeste catarinense, a língua portuguesa tornou-se a língua materna de muitos destes. Nessa tentativa de delimitar língua materna e língua estrangeira para o indígena, destacamos, ainda, que ao manter um contato forte e prematuro com o branco, é possível que uma língua penetre na outra, imbricadas de forma que se tornam heterogêneas e em constante transformação e, inevitavelmente, “deixam marcas do outro naquela que vai constituindo numa - aparentemente [...] língua” (CORACINI, 2007, p. 150).

Assim, ao entender que a língua é constitutiva do sujeito, assentimos com Coracini (2007) ao definir o sujeito como "fruto de múltiplas identificações - imaginárias e/ou simbólicas - com traços do outro que, como fios que se tecem e se entrecruzam para formar outros fios, vão se entrelaçando e construindo a rede complexa e híbrida do inconsciente e, portanto, da subjetividade.” (CORACINI, 2007, p. 61).

Tendo isso em vista, destacamos que a identidade do sujeito se constrói na/através da língua, por isso não existem identidades fixas; as identidades estão sempre em estado de deslocamento. Em contraposição, vemos a identificação “como uma construção, como um processo nunca completado [...]. Ela não é, nunca, completamente determinada - no sentido de que se pode, sempre, "ganhá-la” ou "perdê-la”; no sentido de que ela pode ser, sempre, sustentada ou abandonada” (HALL, 2012, p. 106). O termo identificação nos parece necessário discutir, visto que traz a ideia de (re)construção no deslocamento, por meio da relação com o outro, considerando a multiplicidade de discursos que constituem o sujeito (ECKERT-HOFF; CORACINI, 2010).

Dessa forma, consideramos os processos identificatórios na sua heterogeneidade, na dispersão das múltiplas vozes e dos múltiplos sentidos, no reconhecimento da alteridade, no outro como lugar da significação. Por meio disso, o sujeito entre-línguas-culturas "se vê no e pelo olhar do outro que o constitui, que atravessa seu corpo e se torna sangue e carne, fragmentos dispersos que se juntam e rejuntam, tornando-se semelhantes [...]" (CORACINI, 2007, p. 120).

Assim, presumimos ser essa a condição do sujeito indígena candidato à vaga na UFFS, uma vez que ao assumir essa posição sujeito, permanece em um movimento de entre-línguas-culturas em que ele transita entre sua língua materna - lugar de aconchego - para assumir a língua portuguesa, a língua da academia, a língua do branco que lhe é, de certa forma, imposta. Da mesma maneira, esses sujeitos podem construir novas identificações para ocupar esse lugar. Almejamos interpretar nas análises de que forma os discursos do indígena (re)velam a identidade e identificações deste e também 
na sua escrita, uma vez que "esse ressentimento ou essa implicância o fazem viver, darem sentido à sua existência e lhe imprimem um sentimento de identidade” (GUERRA, 2012, p. 7).

Em relação às redações desse processo seletivo da UFFS, compreendemos que se apresentam como uma possibilidade de escrita de si, conceito trazido de Foucault (2009). Consideramos que a escrita é uma construção subjetiva, em que o autor deixa suas marcas e seus traços no seu dizer. Para tanto, Foucault (2009, p. 143) produz uma metáfora para, assim, explicar o papel da escrita:

[...] é constituir, com tudo o que a leitura constituiu, um “corpo” [...]. E, este corpo, há de entendê-lo não como um corpo de doutrina, mas sim - de acordo com a metáfora muitas vezes evocada da digestão - como o próprio corpo daquele que, ao transcrever as suas leituras, se apossou delas e fêz sua a respectiva verdade: a escrita transforma a coisa vista ou ouvida "em forças e em sangue [...].

Desse modo, compreendemos que o indígena ao escrever a redação no processo seletivo, produz identificações para si mesmo. Sua escrita, além disso, permanece em uma relação tênue com o outro visto que, ao falar de si, o sujeito indígena evoca outros discursos já ditos sobre ele. Outra questão que tomamos como pressuposto ao analisarmos essas redações é que ao escrever sobre si, além de retomar discursos já ditos, esse sujeito também permanece num movimento de “conquista” com o corretor da prova, ou seja, busca incessantemente conseguir a vaga universitária ao enredar o enredo com a pretensão de convencer o outro por meio dos seus argumentos. Com isso, entendemos que “escrever é pois 'mostrar-se', dar-se a ver, fazer aparecer o rosto próprio junto ao outro” (FOUCAULT, 2009, p. 150).

Nessa perspectiva, tratando-se de um caso de escrita de si, afirmamos que ao buscar palavras, as quais são sempre suas e do outro, a fim de definir-se, é que ele se singulariza. Por meio da escrita de si, o candidato indígena do PIN-UFFS tem um espaço de visibilidade, espaço que dá voz e vez àqueles que se mantiveram por muito tempo calados e invisíveis na sociedade. Com tal característica, compreendemos que "é no exato momento em que se submete às expectativas do outro - ou talvez por isso mesmo -, que resvalam, cá e lá, fragmentos, fagulhas candentes da subjetividade que (se) diz” (CORACINI, 2007, p. 24).

Portanto, buscaremos, nas análises das escritas de si, perceber “o atravessamento de discursos e vozes que confrontam a constituição do indígena e do branco e constroem representações de si, do outro e do outro de si [...]” (GARGIONI; GUERRA, 2016, p. 7). Com isso, pretendemos discutir como as escritas de si apontam para traços identificatórios do indígena no tópico a seguir. 


\section{Como um pontinho preto no meio de vários pontinhos brancos: gesto interpretativo das redações do PIN-UFFS (2016)}

Dedicamos nosso estudo a analisar redações produzidas no PIN-UFFS (2016), valendo-nos da Análise de Discurso como dispositivo teórico-analítico de interpretação. Entendemos que a interpretação se constitui da memória discursiva, abarcando outros dizeres já-ditos e que o sujeito reatualiza em seu discurso. Para realizar esse gesto interpretativo, após a digitalização das redações, optamos por fazer a leitura da totalidade do material de arquivo. Por meio dessa análise prévia, foi possível selecionar algumas regularidades.

Ao termos essas marcas de regularidades interpretadas, selecionamos alguns recortes das redações, os quais denominamos, ao longo do texto, por sequências discursivas (SD) para estabelecermos nosso gesto interpretativo. Em relação à redação em si, ressalvamos que no ano de 2016 os candidatos às vagas tinham como temática para dissertar "Desafios e expectativas sobre o ensino superior para os indígenas".

Interpretamos que essas redações configuram um espaço para o sujeito indígena falar de si, da sua constituição linguística e, a partir disso, é possível interpretar identificações deste. Nessa escrita de si, esses participantes buscam "captar o já dito; reunir aquilo que se pôde ouvir ou ler, e isto com uma finalidade que não é nada menos que a constituição de si” (FOUCAULT, 2009, p. 137). Destacamos, ainda, que o critério de seleção das SD se deu por meio de algumas regularidades interpretadas:

a. Ao escreverem sobre língua, os participantes do processo seletivo evidenciam um conflito de estar entre-línguas-culturas, entre a língua indígena e a língua portuguesa;

b. Em relação aos traços identificatórios, é possível interpretar, pela escrita de si desses participantes, que há uma imagem de índio idealizado e que esse sujeito resiste a essa identificação, dessa forma contraidentificando-se;

c. Por último, notamos que há um silenciamento - ou até mesmo, uma interdição - tanto da escola, quanto da universidade.

\section{Conflito entre-línguas-culturas: entre a língua materna e a língua portuguesa}

Para discutir a relação entre línguas, trazemos a primeira sequência discursiva (SD) do corpus na qual destacamos a dificuldade do sujeito indígena, entre-línguas-culturas, tendo que adentrar no lugar que, até então, era do estranho, do diferente:

(SD1) Quando todo indígena, vai para o ensino superior, ele se faz a pergunta e agora, como vou me acostumar sem minha família, e o meu povo. 
Toda faculdade deveria ter um centro cultural para os indígenas para que não possam perder seus costumes. Para todo indígena é importante estudar em uma faculdade, conhecer novas coisas, para que possa um dia voltar para a sua aldeia, e ensinar o que aprendeu. Hoje em dia todo indígena que vai para uma faculdade tem desafios, como por exemplo: se adaptar ao lugar e acostumar falar em português e deixar de falar o seu idioma por um tempo. Para o indígena se acostumar é difícil, mas quando encontrar outros, índios na mesma faculdade é uma alegria, pois vão se sentir a vontade para falar a sua língua. $\left(\mathrm{P} 1^{8}\right)$.

A partir dos enunciados “como vou me acostumar sem minha família, $e$ o meu povo" e "para que não possam perder seus costumes" interpretamos que o sujeito indígena necessita adequar-se ao lugar do outro, do diferente, do estranho. Nessa SD, há um deslizamento de sentidos: se "acostumar" a ficar longe da família, sem "perder" a identificação de indígena que vive na aldeia, que tem seus costumes. Entendemos que é por meio da língua que a identidade do sujeito se constrói, de forma que não há uma identidade fixa; ela sempre está em constante movimento. Nesse sentido, quando esse sujeito ingressa no ensino superior, pode ter seus costumes, os quais são mantidos na aldeia, modificados para habitar o lugar do outro e ser reconhecido pela sociedade. Assim, o sujeito indígena não apaga sua cultura ao entrar em contato com a cultura do branco. Pelo contrário, a nova cultura é entrelaçada à sua, criando, assim, uma nova cultura resultante do hibridismo. E, por meio disso, afirmamos que "é impossível dar como produto acabado e sistematizado a questão da identidade, uma vez que os sujeitos assumem lugares e são constantemente atravessados por uma multiplicidade de vozes [...]” (GUERRA; ALMEIDA, 2016, p. 145).

Observamos na SD1 que o participante utiliza, ao decorrer de sua escrita, verbos reflexivos como "me acostumar", "se adaptar", "se sentir". Esses verbos são aqueles em que o sujeito gramatical é ao mesmo tempo agente e paciente da ação. Ao utilizar de forma constante esses verbos, P1 indica um esforço da parte dele: todo o empenho é dele ao ingressar nesse lugar entre-línguas, é ele quem deve se adaptar. Interpretamos esses recortes como um conflito do entre-línguas-culturas.

Ao abordar que toda instituição de ensino superior necessita ter um “centro cultural para os indígenas”, P1 assume que tem dificuldades em se identificar indígena quando ingressa na universidade, já que a identidade, na sua visão, está ligada ao espaço, aos rituais coletivos. Esse recorte evidencia que não há identidade sem o coletivo, sem o espaço para os indígenas manterem seus costumes. Esse sujeito, portanto, quer seu espaço na universidade, quer participar dessa heterogeneidade por meio de um centro cultural indígena.

Compreendemos, ainda, que no enunciado "para que não possam perder seus costumes” não retrata somente o fato de não quererem perder
${ }^{8}$ A primeira letra (P) indica um sujeito indígena participante do PIN-UFFS (2016), seguida do número (1) que indica a qual redação se refere.

${ }^{9}$ Todas as sequências discursivas estarão em itálico e entre aspas quando forem usadas ao longo do texto. 
seus costumes devido à influência daquele que não é indígena, mas que não podem perder seus costumes, visto que o constituem. Ainda nessa SD, percebemos a marca do imperativo no verbo "poder" em que se filia a uma pertença, não pode, não tem permissão de abandonar seus costumes. Esse sujeito assume a necessidade de permanecer sendo índio, uma vez que caso venha a se perder, deixar de pertencer ao espaço do PIN e ao espaço do indígena, deixa de pertencer a um grupo. Além disso, P1 entende que se não houver um centro cultural para indígenas não há a possibilidade de manter seus costumes e, assim, eles serão perdidos. Tomamos o centro cultural para indígenas como um pedaço da aldeia no espaço do outro, como um espaço de resistência desse sujeito.

Ao mesmo tempo que há essa possibilidade de perder seus costumes para ocupar um lugar na UFFS, o sujeito necessita, no momento de matricular-se na universidade, comprovar pertença a grupo étnico por meio de três documentos: uma declaração da Fundação Nacional do Índio (Funai) e/ou do cacicado ou de outros órgãos de representação indígena, o Registro Administrativo de Nascimento de Índio (RANI) e uma declaração pessoal de pertença a grupo indígena ${ }^{10}$. Além disso, ressalvamos que para participar do processo seletivo, o indígena deve falar e escrever sua redação em língua portuguesa. Nesse caso, novamente, vemos o conflito do entre-língua-culturas, em que o indígena deve provar que é indígena, porém deve falar e escrever em língua portuguesa, mesmo se essa não for sua língua materna.

No enunciado posterior, o candidato destaca que para que "possa um dia voltar para a sua aldeia, e ensinar o que aprendeu” em que ilustra o que afirmamos no tópico 2.1 ao mencionar a expectativa de grande parte dos indígenas em ingressar na universidade para ajudar a sua comunidade, seja em questões financeiras ou, como no caso de P1, em que ele pretende voltar para sua aldeia a fim de ajudar sua comunidade com os ensinamentos obtidos na universidade.

Em relação à língua, $\mathrm{P} 1$, novamente, demonstra um sentimento de não pertencimento ao lugar do não-indígena "se adaptar ao lugar e acostumar falar em português e deixar de falar o seu idioma por um tempo”. Orlandi (2007), ao considerar o silêncio local como intermediário da censura, nos faz interpretar, nessa SD, que o indígena sofre um silenciamento de sua língua e de sua identidade para pertencer àquele lugar. Em outras palavras, a censura é a interdição da inscrição do sujeito em determinadas formações discursivas, proibindo-se esse sujeito de ocupar certos sentidos, certas posições (ORLANDI, 2007). Nesse caso, o candidato sofre esse silenciamento ao “deixar de falar o seu idioma por um tempo". Portanto, ao entendermos que a identidade não é fixa e está em constante movimento, esse silenciamento afeta diretamente esse movimento da identidade.

Da mesma forma, "sabemos que a identidade pode ser imposta, resultar de uma relação de poder, pode ser efeito de dominação; onde alguém
${ }^{10}$ Informações obtidas no Edital $n^{\circ}$ 820/GR/UFFS/2016. Disponível em: $<$ https://www.uffs.edu. br/atos-normativos/ edital/gr/2016-0820> Acesso em: 30 out. 2017. 
sabe a verdade, alguém pode falar em nome do outro [...]" (CORACINI, 2007, p. 49). E é exatamente essa relação de dominação do não-indígena que P1 se refere em “deixar de falar o seu idioma por um tempo" pois essa lhe parece ser a melhor decisão a se tomar ao adentrar no lugar do outro, aquele que exerce a dominação naquele determinado contexto. Contudo, P1 não abandona seu idioma por completo, ao contrário, ele entra no jogo discursivo para dele se valer, mantendo seus traços de identificação já que será apenas “por um tempo”.

Notamos que a(s) língua(s) do sujeito indígena foram e ainda são silenciadas, ao passo que a língua e as palavras do branco são utilizadas pelo indígena para falar de si mesmo (ORLANDI, 2008). De maneira que, ao falar-se, o indígena toma a língua do outro - o não-indígena - para então falar de si mesmo. Esse acontecimento é tão marcante ao P1 que ele destaca que "quando encontrar outros, índios na mesma faculdade é uma alegria, pois vão se sentir a vontade para falar a sua língua", pois compreende que apenas ao entrar em contato com outro índio ele terá a autonomia de falar a língua materna, a língua do grupo - lugar de segurança, de conforto.

À vista disso, tomamos a SD1 como uma possibilidade de escrita de si porque entendemos que “a partir de uma escrita de si, há também uma escrita do outro e de alteridades do mesmo” (GUERRA, 2016, p. 7). Pensando a partir disso, a escrita do P1 demonstra um imbricamento do discurso do outro e o seu, pois se constitui através das representações que emanam do dizer do outro e "possibilitam (re)pensar as imagens inscritas do outro branco na constituição da identidade de si-indígena” (GUERRA, 2016, p. 7). Afetado pelo desejo de tornar-se o outro, decorrente do conflito de pertencer ao lugar do outro, o indígena deixa sua(s) língua e cultura(s) para ser aquilo que o outro deseja ver. E é nisso que consiste o processo de identificação, a tentativa de ser semelhante ao outro e desejar esse olhar do outro. No tópico seguinte, veremos algumas sequências discursivas em que percebemos traços identificatórios.

\section{É índio mesmo: traços identificatórios do indígena}

Da mesma forma, ao discutirmos sobre os traços identificatórios do indígena, mesmo sendo inconscientemente, há imagens já ditas sobre esse sujeito que fazem com que ele assuma essa identificação como sendo sua. Na perspectiva de Coracini (2007, p. 59), “o que somos e o que pensamos ver estão carregados do dizer alheio, dizer que nos precede [...] de nossos antepassados ou daqueles que parecem não deixar rastros”. Ao indagarem a identificação de indígena caracterizado, os candidatos do PIN demonstram certa contradição, visto que desejam manter determinados costumes e determinada cultura em um centro cultural indígena, como mencionamos 
no tópico anterior, mas não querem assumir essa identificação comumente disseminada de indígena idealizado.

Com isso, também ressaltamos que a figura do outro se forma de um grupo que possui características semelhantes entre si, como nesse caso o indígena, que por vezes foi considerado, segundo Guerra (2015, p. 123), “o selvagem, ao longo do processo histórico” e, diante disso, recebe "uma personificação desse conceito do outro”. Essa constituição de identidade do indígena surge, muitas vezes, de discursos do não-indígena, uma criação imaginária da sociedade sobre ele e pode ser observada nas regularidades identificadas nos recortes abaixo, nos quais os participantes demarcam que para aquele que não é indígena só é considerado indígena aquele caracterizado "tal qual é apresentado em programa da TV e em comemorações na escola: com penas, pinturas, arco e flecha” (GUERRA, 2012, p. 13):

(SD2) [...] mostrar a sociedade que para ser índio hoje não precisamos usar penas na cabeça ou cocar para nos identificar como indígena. (P2).

(SD3) Quando se fala em indígena, a primeira imagem que nos vem a cabeça é a de um indivíduo inocente, com vestes de penas e cocar na cabeça, infelismente, a visão da sociedade brasileira sobre nós indígenas é muito ultrapassada [...] (P3).

(SD4) E quando entramos na faculdade muitos não indígenas pensam que não somos índios porque pintamos o cabelo ou nos vestimos bem, e assim por diante. (P4).

(SD5) Com tudo isso vai ter que explica pra algumas pessoas que é índio mesmo, que não mora no mato, como todo mundo pensa, que usa roupas, celular, possui carro, frequenta festas. Assim como uma outra pessoa normal $[\ldots]$ (P5).

Vejamos que, na SD2, os dizeres do participante apontam para uma imagem de indígena que "por mais que esteja inserido na sociedade branca, ainda é visto com estranheza dentro dela; e, se agir de forma incompatível com os costumes indígenas, é também visto de forma negativa [...]” (GUERRA, 2012, p. 3). Ao enunciar "para ser índio hoje” interpretamos que P2 toma como verdade que, para a sociedade não-indígena, apesar dele discordar, atualmente só é índio se o indivíduo usa penas e cocar. O marcador linguístico “hoje”, utilizado por P2, demonstra que antes o indígena precisava usar penas e cocar para provar ao não-indígena que era realmente índio. Diante dessa SD, notamos que ao discutir isso o indígena enfrenta esse imaginário, “o lugar em que o sujeito resiste, em que ele encontra um espaço para, paradoxalmente, trabalhar sua diferença e seus outros sentidos. É uma forma de proteger sua identidade no senso comum [...]” (ORLANDI, 2007, p. 126).

Do mesmo modo, na SD3 o candidato se refere ao indígena como "um indivíduo inocente, com vestes de penas e cocar na cabeça”. Essa descrição, segundo P3, é "a visão da sociedade brasileira sobre nós indígenas” a 
qual ele considera como a sociedade do branco, uma vez que é a sociedade brasileira contra os indígenas os quais não pertenceriam, na visão do colonizador, a esse contexto social. Como consequência, tratando-se de uma escrita de si, vemos que é por meio desses dizeres que dá “[...] ao indígena a oportunidade de usar suas 'próprias palavras' para afirmar-se socialmente” (GUERRA, 2016, p. 14) e enunciar que essa concepção do indígena caracterizado nos dias atuais é “muito ultrapassada”. Essa imagem se produz contraidentificando-se à formação discursiva de indígena caracterizado, já que P3 não assume essa identificação. Ainda no marcador linguístico “muito ultrapassada” observamos que, apesar de ser um pensamento antigo, houve uma época em que os indígenas identificavam-se com essa formação discursiva e que atualmente isso não ocorre mais. Esse recorte afirma que a imagem é uma construção histórica.

Esse imaginário que a sociedade estabelece de que só é indígena aquele idealizado, ocorre da mesma maneira no ensino superior, assim como aponta P4, pois o indígena ao chegar na instituição de ensino, com a predominância de alunos não-indígenas, escutará que "não somos índios porque pintamos o cabelo ou nos vestimos bem”. Verificamos, nesse recorte, que o próprio enunciador desliza de um posição sujeito a outra ao enunciar "não somos índios” no sentido de que, ao se comportar diferente do esperado em um indígena caracterizado - pinturas corporais, penas e cocar - ele deixa de ser índio para tornar-se semelhante ao não-indígena. Considerando como uma escrita de si, P4 ao (se) dizer “[...] (se) constrói, indicia traços de identificações para si e para o outro, 'uma identidade’, ainda que ilusória, que se edifica constantemente na/através da narrativa de (suas) histórias” (STÜBE, 2008, p. 104).

Assumindo que a "identidade se traça em dobradiças, por laços, laces e desenlaces de fios da memória [...]” (ECKERT-HOFF, 2010, p. 104) entendemos que além de estar em constante movimento, a identidade pode se formar de vozes e discursos do outro sobre si. Com isso, evidenciamos que o indígena possa tomar como verdadeiro o discurso do branco sobre ele mesmo. Tal situação é percebida quando o candidato enuncia que quando encontrar com um não-indígena precisará explicar que "é índio mesmo, que não mora no mato, como todo mundo pensa, que usa roupas, celular, possui carro, frequenta festas”. E esse imaginário de que o índio “mora no mato”, a que $\mathrm{P} 5$ se refere, se constrói desses discursos de que o indígena seja primitivo perante o não-indígena. E isso é evidenciado quando o participante encerra sua escrita, considerando que o índio é “como uma outra pessoa normal”, o que sugere que o indígena não é considerado uma pessoa normal e só se torna quando desidentifica-se com o índio caracterizado.

No enunciado "é índio mesmo", P5 provoca um deslizamento de sentidos ao assumir que precisa afirmar que é realmente indígena mesmo quando não se comporta como tal, pois acreditamos que há um comportamento 
esperado segundo o olhar do branco. É na materialidade linguística que "aparecem marcas de um sujeito cuja identidade não pode ser definida, posto que se mistura com outras ou se dilui nelas [...]” (GUERRA, 2012, p. 14). Além disso, percebemos que no marcador discursivo "algumas pessoas” surge um silenciamento da figura do não-indígena não citado no enunciado. Interpretamos essa omissão como "uma tentativa de contenção dos sentidos, uma manobra da resistência [...]” (GUERRA, 2016, p. 12) por parte do indígena que, ao nosso ver, não quer assumir a posição-sujeito de colonizado.

Nas quatro sequências discursivas anteriores, percebemos que a escrita do indígena mobiliza uma representação do branco ligado ao preconceito, à maldade e à não-aceitação do indígena. Nesse sentido, percebemos que esses participantes, ao escreverem o texto proposto pelo processo seletivo, sentem-se inseguros em relação a um possível contato com o não indígena, uma vez que este estranharia sua presença. Entendemos, também, que essa angústia possa surgir "porque o processo de escritura traz consigo o jogo de constituição de identidade” (SCHERER, 2010, p. 108). Essa mesma insegurança do indígena pode ter surgido a partir de um silenciamento de sua língua-cultura, interferindo na sua identidade. Discutiremos mais sobre silenciamentos e interdições nas sequências discursivas abaixo.

\section{Entre silenciamentos e interdições}

Percebemos, ainda, que nas redações existem regularidades em relação ao silenciamento da língua-cultura do sujeito indígena, ou seja, "aquilo que é apagado, colocado de lado, excluído” (ORLANDI, 2007, p. 102). É dessa maneira que entendemos essas sequências discursivas, com a força que o silenciamento exerce sobre a língua e, por consequência, à identidade do indígena, já que este sujeito necessita silenciar-se para habitar o lugar considerado do não-indígena. A seguir, examinemos a SD6 para iniciarmos a discussão:

(SD6) o nosso desafio começa desde o momento que se inicia na primeira série, lá temos que aprender a falar portugues e outros, e a outros costumes. (P6).

Notamos, a partir do enunciado "o nosso desafio" a presença do pronome "nosso", primeira pessoa do plural, em que P6 se coloca na ação, assumindo esse papel como sendo dele e de toda a comunidade indígena a que pertence. Além disso, ao analisar por meio do intradiscurso, notamos o marcador linguístico “lá”, apontando para um sujeito indígena entre-línguas-culturas, que habita o espaço aqui e o espaço lá, transitando em um lugar entre línguas. É nesse mesmo sujeito, que se vê presente o branco, em que nele perpassam fragmentos, vozes e discursos do outro que afetam sua identidade. Esse mesmo marcador linguístico se apresenta como uma 
marca temporal - foi na escola que se deu o marco inicial ao aprendizado da língua portuguesa - e espacial, indiciando para um lugar aqui, lugar do índio e um lugar lá, lugar do branco.

Há também a presença imperativa do verbo ter conjugada na primeira pessoa do plural, no enunciado "lá temos que aprender a falar portugues e outros, e a outros costumes” que filia-se a uma pertença, uma vez que não tem permissão de falar outra língua se não o português. Quando P6 destaca que isso "se inicia na primeira série”, analisamos como uma demonstração de silenciamento causado pela própria escola ao obrigá-lo a aprender o português e não permitir o uso da língua materna. É possível evidenciar o papel da escola em silenciar a língua desse sujeito indígena ao obrigar a aprender e a usar somente a língua portuguesa nesse processo de aprendizagem. Esse impedimento aponta que, ao censurar o sujeito em inscrever-se em determinadas formações discursivas, também se proíbe o sujeito de ocupar determinadas posições e lugares.

Esse silenciamento causado pelo outro ao indígena pode ser observado também na sequência abaixo, na qual o candidato à vaga universitária diz sentir "vergonha” ao falar sua língua materna:

(SD7) tem gente que entra nas universidades e perdem um pouco da cultura, perder a mania de falar sua língua e não porque esquecem e sim por terem vergonha de como os "brancos” vão reagir [...] (P7).

Na SD7, identificamos que, ao contrário da SD6, há um deslizamento em "tem gente que entra nas universidades" no marcador linguístico indeterminado "gente" em que o participante se ausenta do enunciado. Podemos entender que o "gente” se refere a outro indivíduo que não ele, a um sujeito que sofre, fortemente, a interferência do outro. Essa interdição é tão forte que P7 não consegue dizer em primeira pessoa - ou resiste: são os outros que se assujeitam a entrar na universidade e perder a cultura. Ao entendermos que ao falar do outro o sujeito fala de si, P7 lança para o outro essa perda de costumes, mas não se anula totalmente. No recorte "perder a mania de falar sua língua" notamos que o candidato demarca o ato de falar sua língua como uma “mania”, ressoando o discurso da existência de uma língua fechada e homogênea, além de marcá-la como um ato involuntário e constitutivo a ele. Destacamos, ainda, o marcador linguístico "mania" na escrita de P7 como uma prática negativa, algo estranho.

Para exemplificar esse abandono, o candidato aponta em "não porque esquecem e sim por terem vergonha de como os 'brancos'vão reagir”, ou seja, não é da vontade do indígena não falar sua língua materna, mas o faz porque soa vergonhoso diante do outro que desconhece sua língua. $\mathrm{O}$ marcador discursivo "vergonha" tem um efeito de algo inapropriado, que expressa receio em se sentir ridículo em determinada situação. E é exatamente esse sentimento que P7 apresenta, uma sensação de perda da dignidade e de 
humilhação frente ao não-indígena que pode ridicularizá-lo por não falar a língua portuguesa. Nesse sentido, o indígena vê a necessidade de silenciar sua língua e assumir a língua do outro para não acontecer esse constrangimento.

Ademais, notamos que P7 escreve "brancos” entre aspas, o que demonstra uma certa hesitação ao chamar o outro desse modo ou, ainda, o participante quer ironizar essa nomeação de branco dada ao não-indígena, pois acredita que esse branco possa não ser "tão branco" assim. Nesse sentido, essa nomeação entre aspas pode se referir ao imigrante italiano, ao haitiano, ao nordestino, ou melhor, ao aluno da UFFS que não seja indígena. O que se difere da sequência discursiva abaixo, a qual o participante nomeia o outro como "não indígena”, ou seja, aquele que não pertence ao seu grupo, que é diferente dele. Nesse caso, nos referimos a sujeitos históricos que possuem passado e presente, cujos acontecimentos marcam a região fronteiriça (local e global) entre indígena e branco. Problematizamos, na fala de P7, que são os povos indígenas (colonizados), de um lado, e a sociedade hegemônica (colonizadores brancos), de outro.

(SD8) Desde as gerações antigas costumaram a existir sempre esse estranhamento entre a sociedade não-indígena em relação ao indígena, dentro de uma instituição o preconceito é bem visível [...] os não indígenas na maioria das vezes se acham superiores, o preconceito dentro das universidades é enorme, na maioria das vezes deve sentir se como um pontinho preto no meio de vários pontinhos brancos. (P8).

Nessa sequência discursiva, o candidato destaca que "desde as gerações antigas” o indígena sofreu o peso de um olhar estranho vindo do outro e o próprio preconceito da sociedade. Ao entendermos que o indígena é constituído pelo e no olhar do outro, notamos também que para o indígena sobreviver, ele “[...] precisa aceitar o lugar que lhe é concedido, ainda que esse lugar o transforme em objeto de exclusão para o outro: afinal, esse também é um modo de garantir sua existência” (GUERRA, 2012, p. 7).

Ao depararmo-nos com o excerto "dentro de uma instituição o preconceito é bem visível”, compreendemos que a universidade, como instituição de ensino, faz parte dos Aparelhos Ideológicos do Estado (AIE) que funcionam como espaço de materialização da ideologia (ALTHUSSER, 1985). Por meio deles, entendemos que existe uma dominação (nesse caso, do não-indígena) não pela força, e sim pelo uso da ideologia para manter a classe dominante no poder e condicionar o dominado (o indígena) na condição de submissão.

Em seguida, P8 exemplifica o preconceito e esse sentimento de inferioridade diante do branco ao dizer que "deve sentir se como um pontinho preto no meio de vários pontinhos brancos”, salientando que um indígena se sentiria como se fosse, simplesmente, um ponto preto perdido no meio de um vasto número de pontos brancos - que designaria o não-indígena. No entanto, acreditamos haver semelhanças entre o branco e o indígena na 
escrita de P8, uma vez que todos são igualmente pontinhos. Esse recorte aponta para sentidos que historicamente são estabilizados em relação as cores branca e preta. Ademais, percebemos que esse preconceito e estranhamento do branco com o indígena faz com que ele se considere diferente quando comparado aos demais. Nesse mesmo sentido, percebemos que toda essa situação criada pelo P8 é uma suposição criada por ele, devido ao uso do marcador discursivo “deve”, no sentido de supor que isso aconteça, mas sem tomar esse papel como sendo seu.

(SD9) Pois temos que deixar um pouco a cultura de lado para podermos se adaptar a outras maneiras de viver e conviver com os não indígenas. Porque deixar a cultura de lado? Porque quando vamos a outro lugar fora da nossa aldeia junto ao não indígenas não podemos mais falar a nossa língua, porque eles os não índios não entendem. Então temos que tentar responde ou nos comunicar na língua deles. (P9).

Na SD9, o participante começa sua escrita com uma conjunção explicativa "pois", relatando como seria para o indígena sair de sua aldeia e ingressar no ensino superior. Logo no início, P9 diz que para se adaptar aos não-indígenas precisa “deixar um pouco a cultura de lado”, simbolizando que essa mudança seria sutil e em partes. No entanto, na sentença seguinte ele faz uma interrogativa "porque deixar a cultura de lado?" em que contradiz o que foi apresentado anteriormente. Aqui, já não parece que se deixará um pouco da cultura, mas sim afirma que se deixará por completo a cultura para entrar em contato com o branco, demonstrando uma hesitação de P9 sobre isso.

Ainda em relação a esse contato, o candidato informa que para ocupar esse lugar é preciso "se adaptar a outras maneiras de viver e conviver com os não indígenas” diferentes do que ele, como indígena, era acostumado a vivenciar em seu cotidiano. Ademais, no marcador linguístico de caráter injuntivo “temos” percebemos uma interdição do não-indígena, no qual interpretamos que esse sujeito é “obrigado” a deixar sua cultura e se adaptar ao dominador.

Em seguida P9, novamente, desliza ao utilizar os verbos "poder" e “ter”, conjugados ambos em primeira pessoa do plural, demonstrando que o indígena não tem permissão de usar sua língua materna: "não podemos mais falar a nossa língua, porque eles os não índios não entendem. Então temos que tentar responde ou nos comunicar na língua deles”. Interpretamos, por meio dessas marcas discursivas, que não é permitido que esse sujeito fale sua língua, visto que aquele que não é indígena não o compreenderá. Assim sendo, é ele quem precisa assumir a língua do outro para ser aceito naquele lugar e não vice-versa, tornando-se em "um espaço no qual o sujeito se constitui pelos traços culturais em conflito” (STÜBE, 2016, p. 34). Da mesma forma, percebemos que o participante demarca "a nossa língua” como a língua indígena e a "língua deles" como a língua do não-indígena. 


\section{Considerações finais}

Diante do exposto, observamos que ao se inserir no espaço considerado historicamente do outro, o indígena é afetado pela língua-cultura do outro, diferente e estranha. E com isso, permanece em um conflito entre-línguas-culturas, tendo que calar sua língua materna para, então, conseguir transitar nesse espaço considerado do não-indígena. Evidenciamos outro conflito do entre-línguas quando o próprio processo seletivo exige que a redação seja escrita em língua portuguesa, ao mesmo tempo em que exige que o candidato declare ser realmente indígena.

Na escrita de si, interpretamos que esses candidatos sentem-se vítimas do estereótipo e do preconceito daquele que não é indígena que, segundo eles, é percebido ao adentrar na universidade. E isso interfere nos traços identificatórios do indígena, uma vez que assumimos que o sujeito é interpelado no e pelo olhar do outro. Ademais, entendemos que, no discurso do participante do PIN-UFFS, há uma resistência em relação ao indígena caracterizado, aquele com penas na cabeça e no cocar. E, com isso, sofre ao ter que provar que é índio mesmo, pois o "ser índio" vai além da caracterização do sujeito.

Em todo esse trabalho, buscamos analisar o discurso do indígena que, muitas vezes, não teve voz nem vez na sociedade não-indígena. Percebemos, nas regularidades encontradas, esse calar, essa violência e essa incessante busca de provar que é índio em uma sociedade preconceituosa em relação ao diferente. Com isso, retomamos o título que carrega nosso trabalho "índio já sofre por ser índio”, em que é um recorte de um candidato que expressa toda a dor e o sofrimento que esse silenciamento causa nesses sujeitos. E que o simples fato de ser índio já o tornaria um sofredor.

Enfim, faz-se necessário ressaltar que nesse gesto interpretativo muitas considerações puderam ser evidenciadas e possíveis análises foram apontadas. Embora a pesquisa ainda ofereça possibilidades de outras investigações e outros olhares, destacamos que esse sujeito indígena, interpelado pela língua, apresenta um conflito em relação a esta e aos traços identificatórios, uma vez que contraidentifica-se com o indígena idealizado, ao mesmo passo que deseja um espaço de resistência na universidade para manter sua cultura e seus costumes. Do mesmo modo, acreditamos que tanto a escola quanto a universidade, enquanto legitimadoras da língua oficial, silenciam a língua materna do indígena.

Diante disso, comprovamos nossa hipótese de que os participantes do processo seletivo, ao buscarem adequar-se ao lugar do não indígena, sofrem um silenciamento de sua língua e identidade indígena, produzindo um apagamento da sua língua materna. Esperamos, neste trabalho, ter problematizado e (des)construído discursos do não-indígena, na direção de oportunizar ao sujeito indígena, o qual deseja conquistar um espaço no 
ensino superior, falar de si. Além disso, esperamos contribuir em novas pesquisas, novos trabalhos na $\mathrm{AD}$ acerca do sujeito indígena e, ao nosso estudo, colocamos um ponto final.

\section{Referências}

ALTHUSSER, L. Aparelhos Ideológicos de Estado: nota sobre os aparelhos ideológicos de Estado. Tradução de Walter Evangelista. Rio de Janeiro: Edições Graal, 1985. 128 p.

BRASIL. Constituição (1988). Constituição da República Federativa do Brasil. 35. ed. p. 1-446. Disponível em: <http://www.planalto.gov.br/ ccivil_03/Constituicao/Constituicao.htm>. Acesso em: 27 jun. 2017.

Lei $n^{0}$ 9.394, de 20 de dezembro de 1996. Estabelece as diretrizes e bases da educação nacional. Diário Oficial da União, Brasília, DF, 23 dez. 1996. Disponível em: <http://portal.mec.gov.br/seesp/ arquivos/pdf/lei9394_ldbn1.pdf>. Acesso em: 27 jun. 2017.

CORACINI, M. J. A celebração do outro: arquivo, memória e identidade: línguas (materna e estrangeira), plurilinguismo e tradução. Campinas: Mercado de Letras, 2007. 247 p.

DAMBROS, M. et al. Estudantes indígenas na educação superior: o contexto da UFFS. In: EDUCERE: CONGRESSO NACIONAL DE EDUCAÇÃO, 12, 2015, Curitiba. Formação de professores, complexidade e trabalho docente. Educere, 2015. p. 40847 - 40859. Disponível em: <http://educere. bruc.com.br/arquivo/pdf2015/18997_8565.pdf>. Acesso em: 30 jun. 2017.

ECKERT-HOFF, B. M.; CORACINI, M. J. (Org.) Escrit(ur)a de si e alteridade no espaço papel-tela: alfabetização, formação de professores, língua materna e estrangeira. Campinas: Mercado de Letras, 2010.

ECKERT-HOFF, B. M. (Dis)sabores da língua ma(e)terna: os conflitos de um entre-lugar. In: ECKERT-HOFF, B. M.; CORACINI, M. J. (Org.) Escrit(ur)a de si e alteridade no espaço papel-tela: alfabetização, formação de professores, língua materna e estrangeira. Campinas: Mercado de Letras, 2010. p. 79-104.

FAUSTINO, R. C. Política educacional nos anos de 1990: o multiculturalismo e a interculturalidade na educação escolar indígena. 2006. 329f. Tese (Doutorado em Educação) - Centro de Ciências da Educação da Universidade Federal de Santa Catarina, Florianópolis, 2006.

FAUSTINO, R. C. et al. A presença indígena na Universidade: acesso e permanência de estudantes Kaingang e Guarani no ensino superior do Paraná. Revista Cocar, Belém, v. 7, n. 13, p.69-81, jul. 2013. 
FERREIRA, M. C. L. O caráter singular da língua na Análise do Discurso. Organon, Porto Alegre, v. 17, n. 35, p. 189-200, jul-dez. 2003.

FOUCAULT, M. A escrita de si. In: O que é um autor? Tradução de Antônio F. Cascais e Edmundo Cordeiro. 7. ed. Lisboa: Passagens, 2009. p. 127-160.

GARGIONI, A. A. P.; GUERRA, V. M. L. Um olhar foucaultiano sobre a escrit(ur)a de si: o professor Terena na tela do blog. Interletras, Dourados, v. 5, n. 23, p.1-19, set. 2016.

GUERRA, V. M. L. Alunos indígenas: escritura (de si) e (ex)(in)clusão. In: III Simpósio Nacional e I Internacional Discurso, Identidade e Sociedade Dilemas e Desafios na Contemporaneidade, 2012, Campinas. Anais... São Paulo e Campinas: USP e UNICAMP, 2012. v. 3.

GUERRA, V. M. L. O outro (do) lado da fronteira: identidade Kaiowá e território indígena. Cadernos de Linguagem e Sociedade, Brasília, v. 2, n. 16, p.116-139, 2015.

GUERRA, V.M. L.; ALMEIDA, W.D. (Org.) Povos indígenas em cena: das margens ao centro da história. Campo Grande, MS: OMEP/BR/MS, 2016.

HALL, S. Quem precisa de identidade? In: SILVA, T. T. da; HALL, S.; WOODWARD, K. Identidade e diferença: a perspectiva dos estudos culturais. Tradução de: Tomaz Tadeu da Silva e Guacira Lopes Louro. 12. ed. Petrópolis, RJ: Vozes, 2012. p. 103-130.

LIMULJA, H. C. L. R. Uma etnografia da Escola Indígena Fen’Nó à luz da noção de corpo e das experiências das crianças kaingang e guarani. 2007. 138 f. Dissertação (Mestrado em Antropologia Social da Universidade) - Universidade Federal de Santa Catarina, Florianópolis, 2007.

LUCIANO, G. S. O índio brasileiro: o que você precisa saber sobre os povos indígenas no Brasil de hoje. Brasília: MEC, SECAD, LACED/ Museu Nacional, 2006.

ORLANDI, E. P. As formas do silêncio: no movimento dos sentidos. 6 . ed. Campinas: Unicamp, 2007. 181 p.

- Terra à vista: discurso do confronto: velho e novo mundo. Campinas, SP: Unicamp, 2008.

Análise de discurso: princípios e procedimentos. 11.

ed. Campinas, SP: Pontes, 2013.

PAYER, O. M. Processos, modos e mecanismos da identificação entre o sujeito e a(s) língua(s). Gragoatá, Niterói, n. 34, p. 183-196, 2013. 
PÊCHEUX, M. O Discurso: estrutura ou acontecimento. Tradução de Eni Pulcinelli Orlandi. 6. ed. Campinas, SP: Pontes, 2012.

SCHERER, A. E. A escrit(ur)a de si: uma história do sujeito pela alteridade. In: ECKERT-HOFF, B. M.; CORACINI, M. J. Escrit(ur)a de si e alteridade no espaço no espaço papel-tela: alfabetização, formação de professores, língua materna e estrangeira. Campinas: Mercado de Letras, 2010. p. 107-119.

STÜBE, A. D. Tramas da subjetividade no espaço entre-línguas: narrativas de professores de língua portuguesa em contexto de imigração. 2008. Tese (Doutorado em Linguística Aplicada) - Instituto de Estudos da Linguagem, Unicamp, Campinas, 2008.

STÜBE, A. D. "Exilados da própria língua”: a (des)estabilização de fronteiras. In: TFOUNI, F. E. V.; STÜBE, A. D.; PAULON, C. P. (Org) Silêncio e Interdito: discurso em movimento. São Carlos: Pedro \& João Editores, 2016. p. 25-47.

UNIVERSIDADE FEDERAL DA FRONTEIRA SUL. Resolução $\mathbf{n}^{0}$ 033/2013. Institui o Programa de Acesso e Permanência dos Povos Indígenas. Conselho Universitário, 2013. Disponível em: <https://www. uffs.edu.br/atos-normativos/resolucao/consuni/2013-0033> Acesso em: 27 jun. 2017.

Recebido em agosto/2018.

Aceito em janeiro/2019. 